\title{
A CONSTRUÇÃO DE UMA REPRESENTAÇÃO DO CONHECIMENTO E SUA ANÁLISE FILOSỎFICA E PEDAGÓGICA
}

\author{
CONSTRUCTION OF A REPRESENTATION OF \\ KNOWLEDGE AND ITS PHILOSOPHICAL AND \\ PEDAGOGICAL ANALYSIS
}

\author{
Érica Correia da Silva ${ }^{a}$ \\ Maria Celeste Souza de Castrob \\ Dante Augusto Galeffic
}

\begin{abstract}
RESUMO
Introdução: Este artigo relata a experiência de execução de um trabalho proposto pela disciplina Sistemas de Representação do Conhecimento - um dos componentes estruturais do Doutorado Multi-Institucional e Multidisciplinar em Difusão do Conhecimento da Universidade Federal da Bahia - sob um olhar filosófico que reconhece o processo como racionalista e interdisciplinar e que o transcende para uma perspectiva transdisciplinar. Objetivo: Analisar o trabalho proposto, que por sua vez foi pautada na metodologia Problem Based Learning ( $\mathrm{PBL}$ ), desde a construção de padrões, através do formalismo da Lógica Computacional, no software Visual Turing até a produção de evoluções artificiais no software Mirek's Cellebration, visando detalhar como um conhecimento pode ser representado. Metodologia: Pesquisa de caráter qualitativo e descritivo. Resultados: Analisando o processo podemos afirmar que primeiramente evoluímos de um dado à um conhecimento simulado e isto representou um conhecimento, mas é preciso ir além, buscando então sentidos outros para a representação de um conhecimento. Ressaltamo-los do ponto de vista filosófico, computacional e pedagógico chegando á atitude de não conformação com um único caminho - a dedução - para representar um conhecimento. Assim, o nosso desvio se faz através dos fundamentos da transdisciplinaridade. Conclusões: Buscando uma unicidade pautada na educação transdisciplinar concebemos que a atividade realizada nesta disciplina possibilitou ir além do formalismo matemático e de uma simulação computacional, mesmo ressaltando sua grandiosa importância, uma vez que nos

\footnotetext{
a Doutoranda do Programa de Pós-Graduação em Difusão do Conhecimento da Universidade Federal de Bahia (PPGDC-UFBA). E-mail: erica.correiasilva@gmail.com.

b Doutoranda do Programa de Pós-Graduação em Difusão do Conhecimento da Universidade Federal de Bahia (PPGDC-UFBA). Docente de Educação da Universidade do Estado da Bahia (UNEB). E-mail: souzacastrom@gmail.com.

c Doutor em Educação pela Universidade Federal da Bahia (UFBA).Docente do Programa de Pós-Graduação em Difusão do Conhecimento da Universidade Federal de Bahia (UFBA). Email: galeffid@gmail.com.
} 
permitimos sair de uma mente condicionada a uma mente criadora.

Descritores: Representação do conhecimento. Racionalismo. Interdisciplinaridade. Transdisciplinaridade.

\section{INTRODUÇÃO}

Vivemos em busca de conhecimento e graças a ele as sociedades humanas evoluíram chegando ao estado atual da civilização mundial, com sua positividade e com sua negatividade, porque o mesmo conhecimento que cura é aquele que pode matar, pois a energia atômica, por exemplo, tanto pode ser usada em benefício da vida como pode matar. Segundo Gomez (1993), a trajetória do conhecimento humano compõe-se dos solos ontológico, da consciência e da linguagem, o que nos mostra que inicialmente conhecer não passa pelo representar, que é um acontecimento posterior para o qual o mundo só é enquanto é representado e por fim, o representado é produto do conhecimento e independente do sujeito e do objeto do conhecimento. Diante disso, é perceptível que a estruturação do conhecimento se dá pela representação. Mas, o que é representação do conhecimento? Quais as implicações da relação conhecer/representar? São estas indagações que nortearão este artigo, visando respondê-las pelo viés computacional, epistemológico e pedagógico.

As abordagens teóricas, experimentais e analíticas tecidas neste trabalho, são oriundas do conjunto de atividades, aulas e discussões realizadas durante 0 componente curricular Sistemas de Representação do Conhecimento no curso de Doutorado Multi-Institucional e Multidisciplinar em Difusão do Conhecimento $(\text { DMMDC })^{1}$. Este componente curricular objetiva preparar os estudantes para a realização dos processos de análise e representação epistemológica, a partir de modelos formais e/ou informais de criação, organização, gestão e difusão do conhecimento baseados em fundamentos da Lógica e da Matemática tendo como proposta avaliativa a resolução de um problema de caráter interdisciplinar,

\footnotetext{
1 Trata-se de um Programa de Pós-Graduação fruto de uma construção coletiva-colaborativa de um grupo interdisciplinar de pesquisadores sobre a questão da difusão do conhecimento no âmbito da relação conhecimento-sociedade. Tendo como área de concentração a modelagem da geração e difusão do conhecimento com linhas que abordam a Cognição, Gestão e Cultura, o que torna o programa interdisciplinar e multirreferencial.
} 
pautado na metodologia ativa Problem Based Learning (PBL).

Diante da pluralidade de referências necessárias para a compreensão do problema - que será exposto no capítulo voltado para os dados - foi necessário assumir "um luto do saber total" (FROES, 2000) considerando os não saberes que foram trazidos na bagagem de uma formação disciplinar. Para transpor as dificuldades optamos inicialmente pelo caminho do olhar da funcionalidade, ou melhor, o 'como fazer' que se aproxima da vertente metodológica da Interdisciplinaridade, defendido por Japiassu (1976) como um fazer que utiliza de esquemas conceituais e análise de diversos campos do saber a fim de integrá-los e conectá-los para fins comuns. Posteriormente questionamentos de ordem epistemológica e pedagógica nos levaram a compreender o inacabamento e a amplitude do que é uma representação do conhecimento e como podemos ir além.

\section{REVISÃO TEÓRICA}

\subsection{VerTente Filosófica}

$\mathrm{Na}$ busca por modos de representar o conhecimento a disciplina nos apresenta a metodologia ativa Problem Based Learning (Aprendizagem Baseada em Problemas - PBL). A origem desta técnica "dá-se na Universidade McMasters em Hamilton, Canadá, em 1964, depois implantada em várias faculdades de Medicina por todo o mundo, inclusive em outras faculdades como odontologia, saúde pública, psicologia, direito etc." (TIBÉRIO IFLC et al., 2003, p. 78). De forma geral o objetivo do PBL está em produzir conhecimento a partir da discussão em grupo de um problema.

Os autores citados anteriormente pontuam que a teoria do conhecimento que embasa esta metodologia é a racionalista. É interessante ressaltar que uma teoria do conhecimento estrutura-se mediante três questões fundamentais, mencionadas por Araújo (2012) em sua obra Curso de Teoria do Conhecimento e Epistemologia: Quais são as fontes, de onde se origina ou a partir do que é produzido o conhecimento? Será mesmo possível conhecer a realidade? O conhecimento obtido é confiável ou não, com ele se chega à verdade ou não, 
qual o papel da subjetividade e é possível atingir a objetividade? Neste sentido um dos principais representantes do racionalismo - René Descartes - responde estas questões fundamentais, afirmando que "1. A fonte de todo conhecimento é o eu pensante; 2. A realidade externa ao sujeito pode ser conhecida apenas pelo entendimento racional, nunca pelos sentidos ou pela imaginação; 3. A verdade é algo evidente, claro, sempre que se tem uma ideia clara e distinta, ela é verdadeira." (ARAÚJO, 2012, p. 34).

O racionalismo foi um dos novos paradigmas da Filosofia Moderna que visava conhecer a realidade através da razão, buscando assim a certeza e a demonstração sem o uso da experiência. Esta corrente defende a confiabilidade da razão em detrimento dos sentidos, trazendo para o jogo a existência de conhecimentos inatos (a priori). Araujo (2012) complementa está caracterização do racionalismo ao discorrer que ele marca o nascimento de questões sobre o conhecimento, a razão, a experiência, o transcendental, os fenômenos, a realidade factual e os critérios de verdade.

O PBL possui uma interessante característica: seu fundamento interdisciplinar. O termo Interdisciplinar vem sendo discutido desde a década de 1960 quando Georges Gusdorf encaminha a primeira proposta interdisciplinar à Organização das Nações Unidas para Educação, Ciência e Cultura (UNESCO), em 1968. Um movimento que foi gerador de discussões e construções conceituais sobre o tema, Lenoir e Hasni (2004) ressaltam que há distinções conceituais e de utilização da Interdisciplinaridade (ID) quanto à lógica racional, instrumental e subjetiva. Dessas, optamos pela caracterização de Japiassu (1976) e Thissen (2008) através de suas perspectivas de heterogeneidade unificadora e de superação da fragmentação das ciências, respectivamente. Ainda com Thissen "Há uma espécie de inteligência interdisciplinar na ciência contemporânea" (2008, p. 549), o que nos convida a buscar outros referenciais para compreender uma representação de conhecimento.

Nesse sentido, apresentamos um atual campo de estudo acerca de representações de conhecimento, a Engenharia do Conhecimento, que trata da construção de representações computacionais, uma vez que nosso relato de experiência se dá na resolução de um problema de cunho interdisciplinar, porém voltado para uma área geral - a computação. Sendo assim, a engenharia citada 
"define metodologias e ferramentas para adquirir e modelar conhecimento com a finalidade de torná-lo independente das pessoas, formalizá-lo e permitir a apropriação por organizações ou sistemas." (ABEL; FIORINI, 2013, p. 1). Assim, usamos este referencial para entender como seu objeto de estudo - o conhecimento - pode ser representado computacionalmente e qual a relevância disso para a aprendizagem.

Esta engenharia, ao tratar dos aspectos do desenvolvimento de um sistema de conhecimento traz o desafio da construção de bases de conhecimento. Essas bases, segundo Abel e Fiorini (2013), podem ser desenvolvidas para formalizar um conhecimento e capturá-lo, permitir o compartilhamento de experiências e habilidades em uma organização ou dar suporte ao raciocínio de sistemas especialistas, sendo elas: a aquisição de conhecimento, a modelagem conceitual e a representação do conhecimento, passos estes que consideramos ter desenvolvido durante a disciplina.

\subsection{Vertente Computacional}

Nesta subseção será exposto um breve apanhado sobre Máquina de Turing, Autômatos Celulares e Evoluções Artificiais, que por sua vez foram temas cruciais para o desenvolvimento do trabalho proposto.

\subsubsection{Máquina de Turing}

As afirmações que as operações matemáticas tramam 0 universo contemporâneo e, que sua linguagem domina o mundo na atualidade, são oriundas de tempos e contextos diferentes. Pierry Lévy (1993), em "As Tecnologias da Inteligência", afirmou que no final do século XX estava emergindo um conhecimento por simulação e em meados do século XXI Harari (2016) em "Homo Deus: Uma breve história do amanhã", apresenta o dataísmo como noção excêntrica, porém real de que o "Universo consiste num fluxo de dados e o valor de qualquer fenômeno é determinado por sua contribuição ao processamento de dados". (HARARI, 2016, p. 370)

Estes paradigmas estão alicerçados na ideia inicial de representação 
algorítmica de Alan Turing - matemático criptoanalista e cientista da computação britânica - que para responder sua inquietação teórica de conceber cálculos diante de uma memória humana limitada, cria um modelo abstrato conhecido como Máquina de Turing (MT). Sua ideia de cérebros eletrônicos capitaneados constitui o primeiro fundamento da Ciência da Computação.

Em sua trajetória intelectual, Turing construiu um arcabouço teórico sobre o calculável e o incalculável. Hopcroft, Ullman e Motwani (2002) apontam como objetivo de Turing, a descrição exata sobre o limite de uma máquina de computação. Acreditamos que a questão que norteou o pensamento deste matemático foi em torno do que uma máquina podia fazer e o que não podia fazer. Este é considerado como elemento fundante dos avanços nas máquinas reais da atualidade. No documento "On Computable Numbers, witch an apllication to the entscheidungs problem" publicado em 1936, se encontram os fundamentos sobre o qual está amparada a ideia da MT, com sua estrutura conceitual composta por memória, estados e transição apresentando-se como uma máquina determinística que segue instruções, a partir de $n$ configurações dadas, tendo como princípio a lógica matemática e considerações sobre o limite da memória humana para computar um número finito de posições. No sentido apresentado por Turing a lógica é vista como um sistema de representação do pensamento humano.

De instruções simples e determinísticas à possibilidade de existência de MDT não determinísticas, o pensamento humano evoluiu e as tentativas de que o universo poderia de alguma forma operar como um programa, ora caíram em descrédito, a exemplo do que aconteceu nas décadas de 1960 e 1970, e, em outros momentos evoluíram, a exemplo de programas simples que são utilizados na nova ciência de Wolfram (1982) que amplia a simulação computacional de sistemas finitos, os autômatos celulares.

\subsubsection{Autômatos Celulares}

Os autômatos celulares podem representar muitos sistemas evolutivos, pois são representações que utilizam computação descentralizada e regras 
simples, tendo diversas aplicações nos mais variados ramos da ciência, em especial, na Biologia, Química e Física. Aplicações estas baseadas nos trabalhos de Neumann, Conway e Wolfram - autor pelo qual daremos ênfase.

Stephen Wolfram (1982) apresenta uma classificação dos autômatos celulares construída a partir da simulação computacional de sistemas finitos, com condições de fronteira periódicas. Em sua definição autômatos celulares são formados por uma rede de células que possuem estados alterados de acordo com o seu estado anterior evoluindo a passos discretos de tempo. A partir dessa teoria, os autômatos celulares passaram a ser vistos como ferramentas que podem representar quase todos os sistemas evolutivos imagináveis.

Tomando por base a classificação das quatro classes empíricas de Wolfram, em Castro e Castro (2008) são apresentadas diversas características dos autômatos: homogeneidade - regras iguais para todas as células; estados discretos - cada célula pode estar em um dos finitos estados possíveis; interações locais - estado de uma célula depende só do seu estado anterior e dos estados das células vizinhas; dinâmicas determinísticas - em cada instante de tempo a célula sofre uma atualização no seu estado e paralelismo - células evoluem de forma autônoma e independente.

$O$ advento das aplicações dos autômatos em computadores modernos tornou possível representar diferentes tipos de dados, números, textos, imagens e praticamente tudo, indicando que é possível pensar em alguns processos que seguem regras definitivas a despeito do tipo de elementos envolvidos. Assim, torna-se razoável pensar em processos da natureza na dinâmica das computações.

\subsubsection{Evoluções Artificiais}

A comparação de um ser vivo com uma máquina é impactante diante das nossas próprias crenças e concepções de mundo e de existência, o que na atualidade está cada vez mais sendo idealizada e fortalecida. Nesse contexto, o biólogo Richard Dawkins, promoveu estudos relativos à teoria da evolução artificial, fundamentados no Darwinismo, afirmando querer "persuadir o leitor de que a visão de mundo darwiniana não é apenas verdadeira, mas é também a 
única teoria conhecida que poderia em princípio solucionar o mistério da nossa existência". (DAWKINS, 2001, p. 3) Assim, ele defende a ideia de que a complexidade e a sincronicidade da vida requerem processos não aleatórios. É a partir da teoria da evolução artificial que este estudioso constrói uma programação computacional baseada na seleção artificial e cumulativa, com pequenos processos de mutação que geram determinados designs.

Os experimentos de Dawkins se concentraram em reproduzir em modelagem computacional o processo de evolução dos seres vivos. Os sistemas eram alimentados com "gens" que originaram "árvores" (representação gráfica estética), gerando criaturas virtuais denominadas "biomorfos". Em suas palavras, "biomorfo é o nome cunhado por Desmond Morris para as vagas formas semelhantes a animais que figuram em suas pinturas surrealistas". (DAWKINS, 2001, p. 61)

Na sua obra citada nesta seção, Dawkins desenvolve a "terra dos biomorfos". Antes de apresentá-la, revela como ela foi construída. A ideia inicial é que as mudanças no processo evolutivo ocorrem de maneira gradual e simples e está estritamente vinculada à complexidade do produto final, onde "o processo cumulativo é dirigido pela sobrevivência não aleatória" (DAWKINS, 2001, p. 48). $O$ acaso, nesse contexto, é secundário, sendo a seleção cumulativa o fator primordial, corroborando para a quebra do entendimento errôneo do darwinismo como uma "teoria do acaso".

\section{RESOLUÇÃO E ANÁLISE DO PROBLEMA PROPOSTO}

Nesta seção apresentamos uma sucinta descrição do problema proposto pela disciplina, mediante a metodologia Problem Based Learning (PBL), bem como as etapas de sua resolução seguida de uma análise computacional, filosófica e pedagógica dos achados, tendo como ponto de partida nossos discursos pessoais intercalados com autores que nos foram apresentados nas disciplinas cursadas no doutorado. 


\subsection{O PROBLEMA}

Visto que o percurso de produção de conhecimento acerca da Natureza está pautado em decifrar comportamentos e demasiadas estruturas complexas, a disciplina Sistemas de Representação do Conhecimento propôs como atividade avaliativa que contribuíssemos nesta temática objetivando a aprendizagem de diferentes assuntos abordados no curso utilizando para tanto a metodologia PBL. Foi proposto então que produzíssemos um padrão por modelagem computacional que explicasse o padrão real da figura abaixo, através de uma regra de autômato celular.

Figura 1 - Concha real

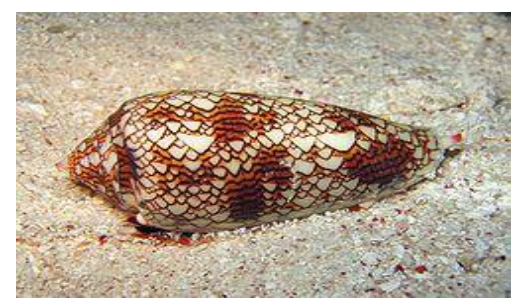

Fonte: Meinhardt apud Nussenzveig (2003, p. 92)

Para esta produção foi solicitado pelos docentes a utilização de um rústico dispositivo teórico, ou melhor, a máquina abstrata de Turing, o que geraria uma "semente". Desta teríamos que observar sua evolução artificial e identificar possíveis criaturas virtuais - os chamados biomorfos. Neste contexto a disciplina traz as seguintes questões de aprendizagem: Como programar a Máquina de Turing? Como definir uma regra de autômato celular elementar? Os biomorfos são modelos evolutivos?

\subsection{EtAPAS dA RESOLUÇão}

Como já fundamentado anteriormente, os autômatos celulares podem representar muitos sistemas evolutivos mediante computação descentralizada e regras simples, tendo diversas aplicações nos mais variados ramos da ciência. Wolfram ao estudar autômatos celulares que partindo de uma linha inicial de células evolui a passos discretos de tempo, criou várias regras. Reproduzimos uma delas: a Regra 90 ou CAR 90, que consiste em um dos oito autômatos 
celulares elementares aditivos. Devido à equivalência dos sistemas simulados por autômatos celulares à uma Máquina de Turing, criamos a regra no software Visual Turing (Versão 2.0) ${ }^{2}$. A CAR 90 possui o seguinte padrão de preenchimento das células:

1. Se tanto a célula da esquerda, quanto a da direita estiverem preenchidas, ou ambas vazias, a célula atual não será preenchida;

2. Se somente uma das células, seja a da esquerda ou a da direita, estiver preenchida, a célula atual será preenchida.

Resultando no seguinte formato:

Figura 2 - Regra de autômato celular e sua execução.

rule 90
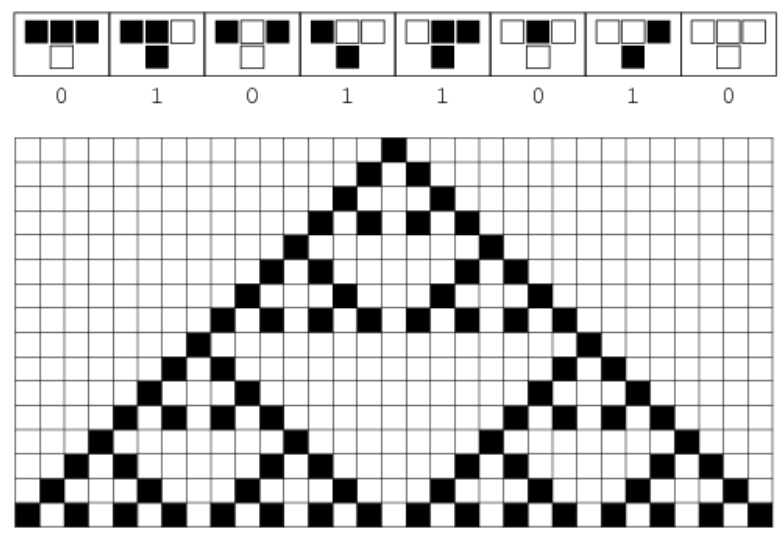

Fonte: http://mathworld.wolfram.com/Rule90.html

Podemos observar também que existe um dispositivo lógico que simula esse modelo, a chamada Porta Lógica XOR:

Figura 3 - Configuração da porta lógica XOR.

PORTA OU EXCLUSIVO (XOR) $\mathrm{C}=\mathrm{A} \oplus \mathrm{B}$

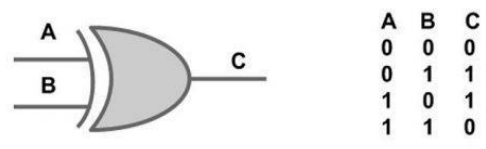

Fonte: https://www.embarcados.com.br/xor/

Assim, uma porta XOR é definida do seguinte modo:

2 https://visual-turing-machine.soft112.com/download.html. 
- Se todas as entradas forem iguais, a saída é zero;

- Se todas as entradas não forem iguais, ao menos uma delas for diferente, a saída é um.

Essa lista de ações foi estruturada no Visual Turing do seguinte modo:

Figura 4 - Estruturação da execução da regra 90 no Software Visual Turing

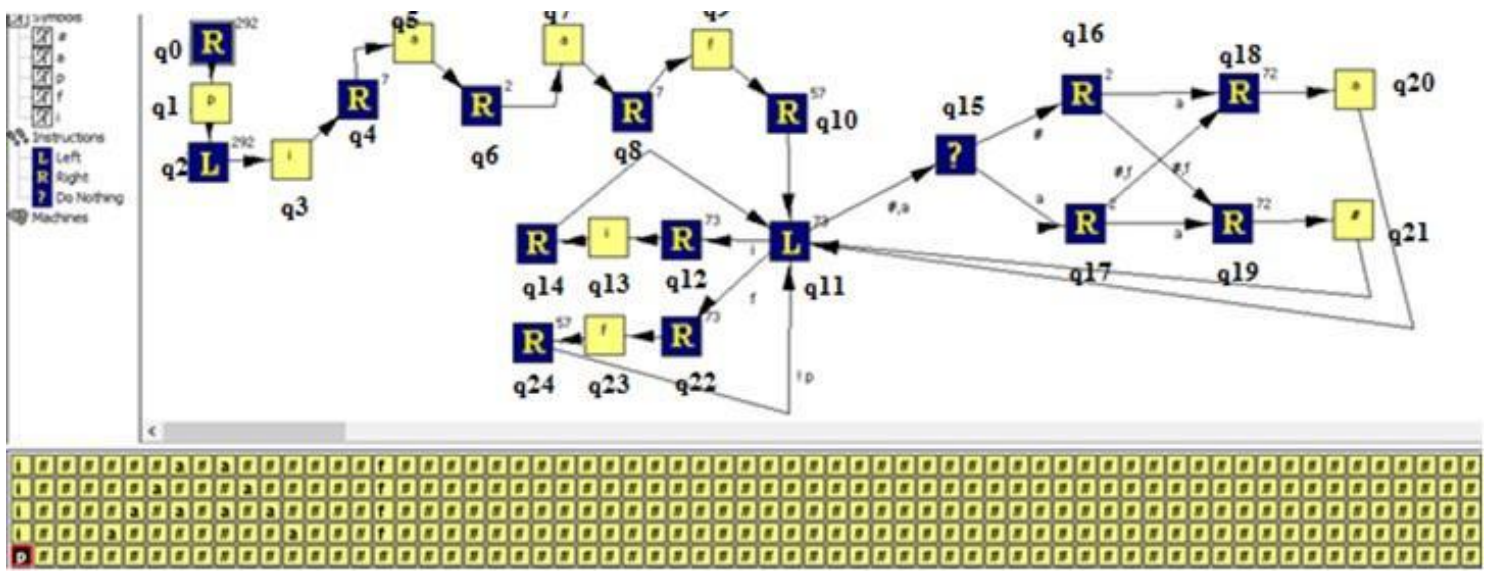

Fonte: Elaborada pelos autores.

Para melhor sofisticação das ações, criamos a máquina geral abaixo:

Figura 5 - Síntese através de submáquinas da estruturação da regra 90 no Visual Turing.

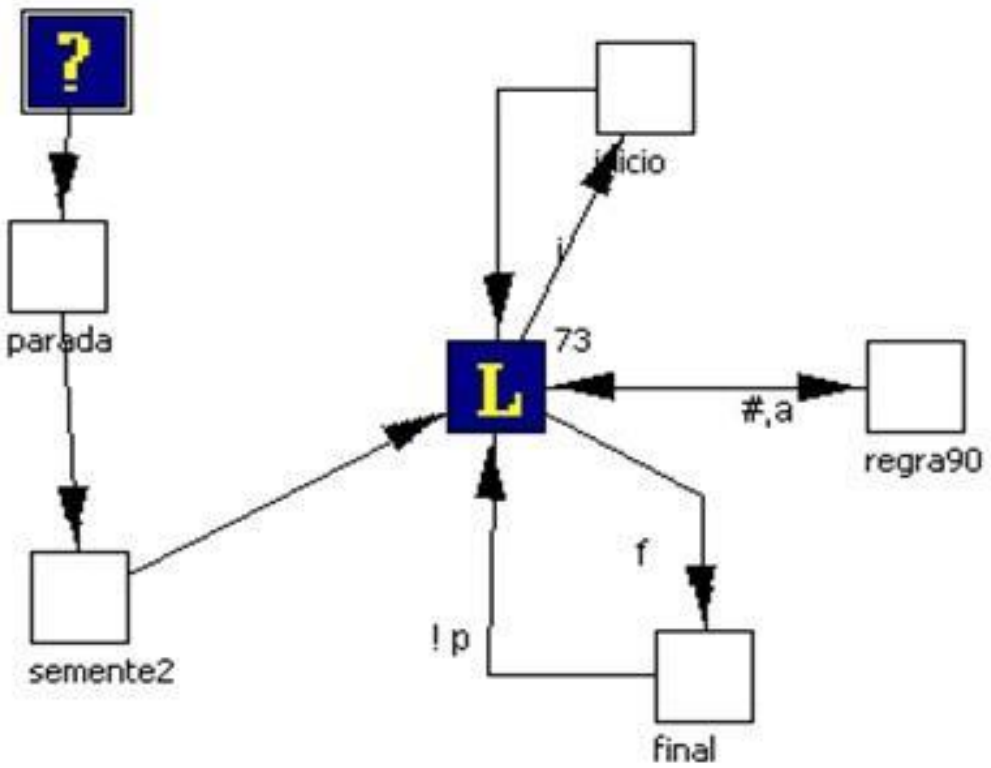

Fonte: Elaborada pelos autores

Nesta máquina geral, temos 5 submáquinas: 
- PARADA: Que representa a delimitação do nosso espaço métrico para criação do padrão proposto;

- SEMENTE 2: Representa a configuração escolhida para fita inicial;

- INÍCIO: Delimitação inicial das fitas;

- FINAL: Delimitação final das fitas;

- Regra 90: Operação lógica de decisão.

Desse modo, pudemos inferir que a Lógica foi o formalismo utilizado para representar o conhecimento de um autômato celular. No caso deste estudo foi gerado a Figura abaixo, após execução da programação, uma semente 4 x 9 que será usada nas seções seguintes:

Figura 6 - Semente criada no Visual Turing

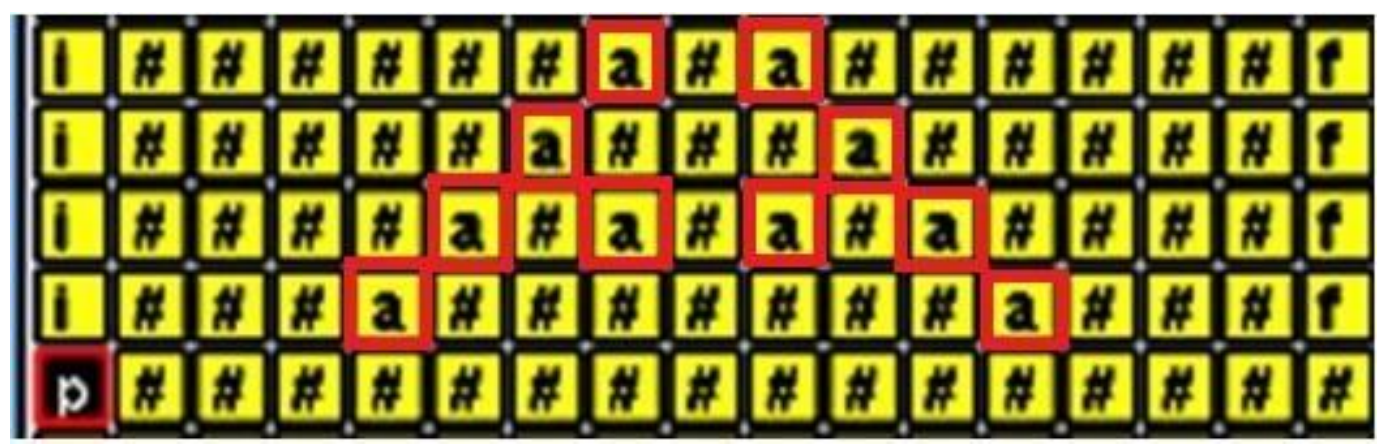

Fonte: Elaborada pelos autores.

$\mathrm{Na}$ construção coletiva desta primeira ação o questionamento voltou-se para: Houve representação de conhecimento? $O$ fato de buscar uma referência humanística para interpretar a estrutura que foi gerada desviou o nosso olhar sobre a importância de perceber que a utilização de dados brutos, 0 e 1 e suas combinações transformaram-se em informação e desta em um conhecimento por simulação, como afirma Lévy (1993) ao apontar a simulação como um modo de conhecimento próprio da cibercultura, definindo-a como "uma tecnologia intelectual que amplifica a imaginação individual e permite aos grupos que compartilhem, negociem e refinem modelos mentais comuns, qualquer que seja a complexidade deles." Analisando o processo podemos afirmar que evoluímos de um dado à um conhecimento simulado e isto representou um conhecimento. 
Complementando a questão inicial, divagamos: Qual o sentido dessa representação simulada?

Para responder pensamos do ponto de vista filosófico, computacional e pedagógico. No primeiro, concebemos que reproduzimos o pensamento filosófico que defende que o conhecimento da realidade tem sua trajetória do abstrato para o concreto. Um princípio cartesiano que "rejeita que o conhecimento dependa dos sentidos ou da imaginação, sem que o entendimento participe". (ARAÚJO, 2012, p. 30) norteou nossos passos se revelando insuficiente para compreender o real sentido deste feito.

Por outro lado, do ponto de vista computacional, mediante fundamentos da engenharia do conhecimento corroboramos com Abel e Fiorini (2013) quanto à compreensão de que representamos um conhecimento, pois eles defendem que é a forma simbólica de formalizar um modelo conceitual que foi fruto de um processo de aquisição de conhecimento. Para além da descrição acima, apresentaremos as implicações de cunho pedagógico.

Visto que padrões decorativos permeiam a natureza, muitos pesquisadores se debruçam neste ramo de investigação. Alan Turing, por exemplo, em The Chemical Basis of Morphogenesis (A Base Química da Morfogênese), de 1952, investigou principalmente através da matemática, a razão pela qual alguns organismos vivos desenvolvem determinadas formas. Em The algorithmic beauty of sea shells (A beleza algorítmica das conchas do mar) o autor Hans Meinhardt (2009) - pioneiro no campo da biologia teórica - reconstrói processos que formam os padrões nas conchas de caracóis marinhos tropicais em simulações de computador observando que estes padrões vão além da beleza, pois contam uma história de desenvolvimento biológico. Na figura VII temos um exemplo presente em sua obra: 


\section{Figura 7 - Concha e seu padrão}

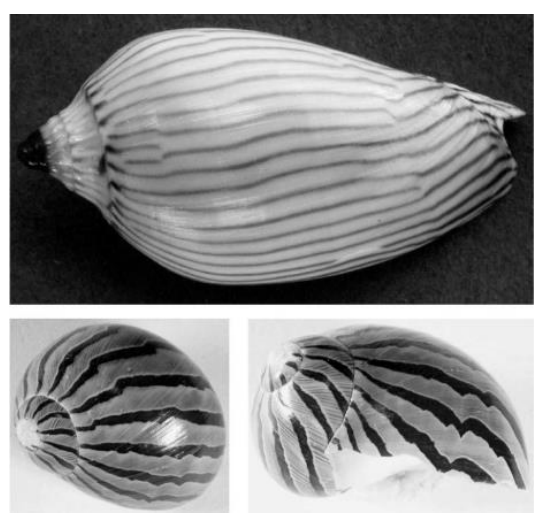

Fonte: Meinhardt, 2009.

Visando dar sequência às pesquisas citadas anteriormente, simulamos processos de formação de padrões da natureza, em específico, desings animais, fundamentado no processo de evolução artificial de Richard Dawkins, que por sua vez se baseia no desenvolvimento embrionário da vida real. Assim, "o desenvolvimento embrionário é um processo tão elaborado que não pode ser simulado com realismo em um pequeno computador. Temos que representá-lo por um processo análogo simplificado. Precisamos descobrir uma regra simples de desenho que o computador possa seguir com facilidade e que possamos fazer variar sob a influência de genes." (DAWKINS, 2001, p. 58)

Para tanto utilizaremos o software Mirek's Cellebration ${ }^{3}$. Este programa por sua vez tem como objetivos explorar e elaborar novas regras e padrões de autômatos celulares em uma ou duas dimensões. A versão utilizada nesta pesquisa comporta 14 famílias de autômatos celulares compostas por inúmeras subfamílias. Destas, escolhemos a família Generations (Gerações), cujo comportamento aproxima-se ao da família Life - Regra definida na forma "S / B", onde $\mathrm{S}$ : define contagens de vizinhos vivos necessários para uma célula sobreviver, B: define contagens de vizinhos vivos necessários para uma célula nascer - mas com um acréscimo na história das células, pois as células que morrem em Life ficam mais velhas nessa família. Porém as células não podem dar origem a novas células, mas ocupar o espaço da rede, mudando

\footnotetext{
3 http://www.mirekw.com/ca/download.html.
} 
radicalmente as regras. Esta família possui um grupo de subfamílias. Destas, escolhemos a denominada Faders.

Para gerarmos evoluções artificiais inserimos a semente (S) gerada após execução da CAR90 no programa MCell. A partir de agora "O olho humano tem um papel ativo a desempenhar nesta história. Ele é o agente selecionador. Examina a ninhada de crias e escolhe uma que irá se reproduzir. A escolhida torna-se então genitora da geração seguinte, e uma ninhada de suas crias mutantes é mostrada simultaneamente na tela." (DAWKINS, 2001). A evolução produzida pela aplicação da regra da família citada faz uma analogia à evolução simulada por Dawkins (Figura VIII) e exibe um design bem conhecido.

Figura 8 - Exemplo de evolução artificial.

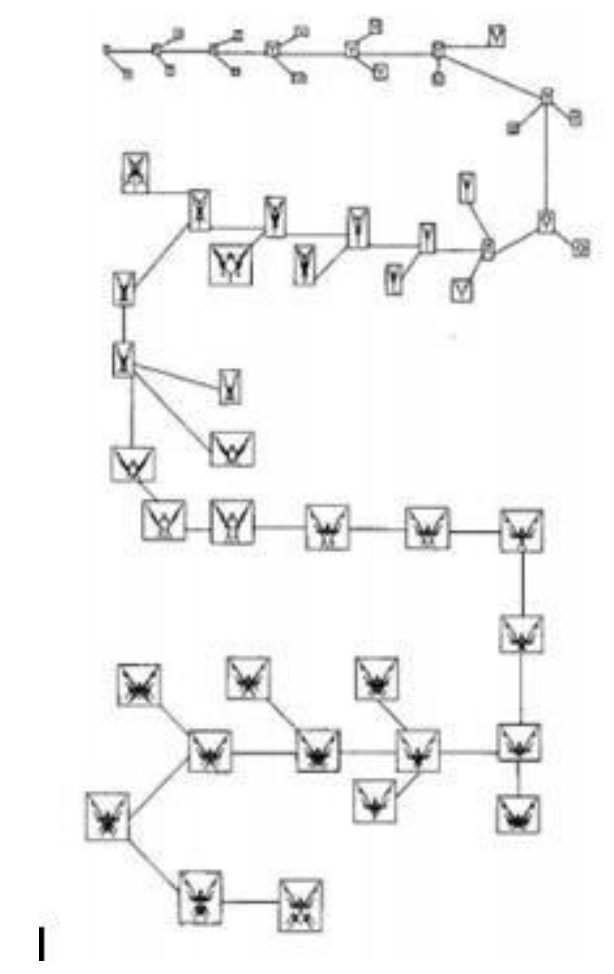

Fonte: Dawkins, 2001, p. 66

Assim, apresentamos na figura abaixo a evolução artificial proveniente da execução da família Generations, subfamília Faders: 
Figura 9 - Evolução artificial no Software Mirek's Cellebration

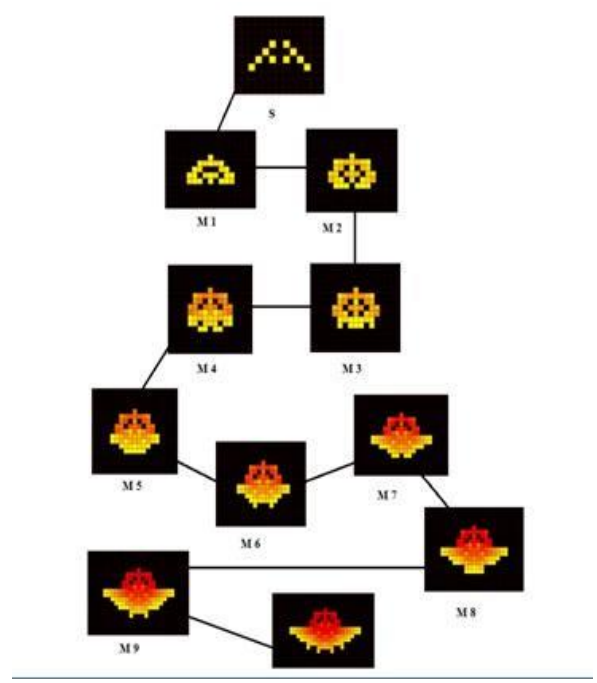

Fonte: Elaborada pelos autores

Associamos o design produzido com um morcego, como podemos ver na figura:

\section{Figura 10 - Morcego real}

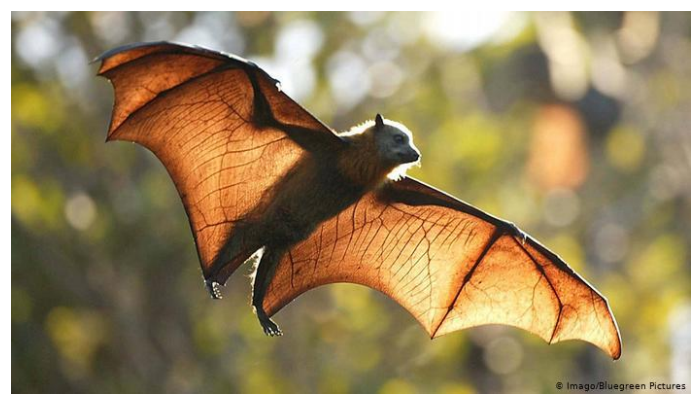

Fonte: https://www.dw.com/en/australia-heat-wave-brain-frying-bats/a-42078045.

Do ponto de vista disciplinar cumpriram-se as questões de aprendizado propostas pelo coletivo dos professores responsáveis pela disciplina. Porém, referenciado por Dimenstein e Alves (2011) consideramos que o desejo de aprender mais norteou a travessia pela disciplina e neste sentido fomos bons e maus estudantes. Do primeiro, pelo cumprimento do programa proposto através da solução do problema dado e cumprimento das questões de aprendizado. Do segundo, pela atitude de não conformação com um único caminho - a dedução - para representar um conhecimento, como exposto em sua fala porque "tínhamos uma enorme voracidade por coisas que não estavam no programa". Buscando entender qual a importância de sair da dedução e ir além, como nos 
aponta GALEFFI (2017) que dialogamos com a Educação Transdisciplinar.

Em Galeffi e Soares (2005) buscamos os fundamentos filosóficos da educação transdisciplinar. Para eles, na perspectiva transdisciplinar os seres humanos são complexos e não podem ser reduzidos a objetividades racionais abstratas. E isto na medida em que somos seres inteligentes e sensíveis simultaneamente, o que mostra como a aprendizagem humana não se resolve por maquinação e repetição apenas, pressupondo o ser sensível aberto ao desenvolvimento de seu mistério, enquanto vive e compartilha da compreensão de si em sua doação própria e apropriada, durante o seu florescimento vital e suas circunstâncias. Esta compreensão abriu-nos para uma experiência de conhecimento em que nos deparamos com questões que ultrapassam a métrica quantitativa e a dedução matemática. Contudo, aqui não se trata de adotar uma forma de polarização, o que significa a importância e reconhecimento do conhecimento dedutivo, e por isso o nosso desvio transdisciplinar incorpora a lógica do terceiro incluído quando se trata de considerar as questões propriamente humanas, vividas por seres humanos concretos. Significa compreender a relação dialógica entre os extraordinários problemas de cálculo e mensuração e de construção de modelos matemáticos evolutivos e os problemas relativos ao ser complexo que somos como seres afetivos, emocionais e sensíveis, seres éticos, morais, que desenvolvem valores e processos de qualificação de modo semelhante aos processos matemáticos de quantificação e calculabilidade, mas que são regidos por outras lógicas

Nessa perspectiva encontramos o fio que nos leva a romper com a visão única de mundo em que apenas a matemática o modela. Dando espaço ao nosso florescimento de um ser que está aberto a unificar seu conhecimento através da articulação de elementos que passam entre, além e através das disciplinas, estimulando uma nova compreensão da realidade, em que "não somente para que ele possa ativar a capacidade de adquirir conhecimentos filosóficos/científicos/técnicos como também para que possa ativar a capacidade de conhecer, através da vivência do autoconhecimento ou da arte de aprender". (GALEFFI e SOARES, 2005, p. 7) 


\section{CONCLUSÃO}

Das indagações pontuadas neste artigo, trazemos algumas considerações. Quanto à questão o que é representação do conhecimento, consideramos uma amplitude de caminhos para respondê-la, uma vez que o representar pode se dá por diferentes teorias do conhecimento.

Se partirmos da ótica racionalista, a representação é a estruturação de conceitos, linguagens e modelos guiados unicamente pela razão, como vimos na criação lógica de Turing, em que partindo de dois conceitos excludentes formulou a base inicial para a representação computacional, sendo esta ampliada por Stephen Wolfram e Richard Dawkins, por exemplo. Porém reconhecemos que outras óticas poderiam defini-la, como a idealista, a realista, a empirista, a idealista crítica, a pragmática, dentre outras.

Partindo do ponto vista computacional reconhecemos que neste século 0 ativo mais importante são configurados em dados que por sua vez estão ditando a forma de conhecer e representar conhecimentos, fortalecendo o conflito homem $\mathrm{x}$ máquina e tornando opaca a dialética que permeia a realidade.

Buscando uma unicidade pautada na educação transdisciplinar, concebemos que a aprendizagem baseada em problemas realizada durante a disciplina descrita possibilitou ir além de uma simulação computacional, uma vez que nos permitimos a partir de inquietações, questionar o porquê, como e para quê do processo e da avaliação realizada. Destas, concluímos saindo de uma mente condicionada a uma mente criadora, um exercício que nos fez amadurecer enquanto aprendentes. Assim, ao lado de um determinismo modulado pela representação matemática há também o mundo da liberdade com sua dinâmica temporal própria e apropriada. E talvez, concordando com alguns filósofos modernos, há níveis de Realidade e de percepção que se encontram ainda além das representações, o que já é motivo para se afirmar que estão fora do alcance do conhecimento racional possível. Mas há também o mistério da existência que não para de surpreender e de provocar admiração, e este não parece ser irracional e sim suprarracional, o que não nos cabe falar, mas não nos impede de contemplar. 


\section{REFERÊNCIAS}

ABEL, Mara Abel; FIORINI, Sandro Rama. Uma revisão da engenharia do conhecimento: evolução, paradigmas e aplicações. Revista International Journal of Knowledge Engineering and Management. v.2, n.2. 2013. Disponível em:

http://incubadora.periodicos.ufsc.br/index.php/lJKEM/article/view/2136. Acesso em: 12 dez. 2019.

ARAÚJO, Inês Lacerda. Curso de teoria do conhecimento e epistemologia. Barueri, SP: Minha Editora, 2012. ISBN 978-85-7868-028-2.

CASTRO, Marcia Luciana Aguena; CASTRO, Reinaldo de Oliveira. Autômatos Celulares: Implementação de Von Neumann, Conway e Wolfram. Revista de Ciências Exatas e Tecnologia, v. 3, n. 3, 2008.

DAWKINS, Richard. Acumulação de pequenas mudanças. In: DAWKINS, Richard. O relojoeiro cego: a teoria da evolução contra o desígnio divino. Tradução de Laura Teixeira Motta. São Paulo: Companhia das Letras, 2001.

DIMENSTEIN, Gilberto. ALVES, Rubem. Fomos maus alunos.11. ed. Campinas, SP: Papirus, Mares 2008.

FRÓES, Teresinha. Sociedade da informação, sociedade do conhecimento, sociedade da aprendizagem: Implicações ético-politicas no limiar do século. In: LUBRISCO, Nidia M. L. (org.). Informação e Informática. Salvador: EDUFBA, 2000.

\section{GALEFFI, Dante. Recriação do Educar: Epistemologia do educar Transdisciplinar. Editora Novas Edições Acadêmicas, 2017.}

GALEFFI, Dante; SOARES, Noemi Salgado. Fundamentos filosóficos da educação transdisciplinar. In: Congresso Mundial de Transdisciplinaridade, 2., 2005. Anais [...] Espirito Santo, 2005. Disponível em:

http://cetrans.com.br/assets/artigoscongresso/Dante_Augusto_Galeffi_e_Noemi _Salgado_Soares.pdf. Acesso em: 23 mar. 2021.

GOMEZ, Maria Nélida González de. A representação do conhecimento e o conhecimento da representação: algumas questões epistemológicas. Revista Ciência da Informação, v.22, n.3. 1993. Disponível em:

http://revista.ibict.br/ciinf/article/view/479.

HARARI, Yuval Noah. Homo Deus: Uma breve história do amanhã. São Paulo: Companhia das Letras .2016

HOPCROFT, J.E.; MOTWANI, R.; ULLMAN, J.D. Introduction to automata theory, languages, and Computation. 2nd Edition, Addison-Wesley, 2000. 
JAPIASSU,Hilton. Interdisciplinaridade e patologia do saber. Rio de Janeiro: Imago, 1976.

LENOIR, Y., HASNI, A. "La interdisciplinaridad: por un matrimonio abierto de la razón, de la mano y del corazón", Revista Ibero-Americana de Educación, №. 35,2004

LÉVY, Pierre. As tecnologias da inteligência: O futuro do pensamento na era da informática. Rio de Janeiro: Editora 34, 1993.

MEINHARDT, Hans. The algorithmic beauty of sea shells. Editora Springer. Ed. 4, 2009.

THIESEN, J. S. A Interdisciplinaridade como movimento articulador do ensino-aprendizagem. Revista Brasileira de Educação, v. 13, n. 39 set./dez. 2008.

TIBÉRIO, I. F. L.; ATTA, J. A.; LICHTENSTEIN, A. O aprendizado baseado em problemas - PBL. Revista de Medicina, São Paulo, v. 82, n. 1-4, p. 78-80, jan./dez 2003.

TURING, A. M. The Chemical Basis of Morphogenesis. Philosophical Transactions of the Royal Society of London. Series B, Biological Sciences, v. 237, n. 641, 1952. Disponível em:

http://www.dna.caltech.edu/courses/cs191/paperscs191/turing.pdf. Acesso em: 23 fez. 2020

WOLFRAM, S. Cellular automata as simple self-organizing systems. Technical report. Caltech preprint CALT. Passadena California, 1982, p. 68938.

\title{
CONSTRUCTION OF A REPRESENTATION OF KNOWLEDGE AND ITS PHILOSOPHICAL AND PEDAGOGICAL ANALYSIS
}

\begin{abstract}
Introduction: This article reports the experience of performing a work proposed by the Knowledge Representation Systems discipline - one of the structural components of the Multi-Institutional and Multidisciplinary Doctorate in Knowledge Dissemination of the Federal University of Bahia - under a philosophical perspective that recognizes the process. as rationalist and interdisciplinary and transcending it to a transdisciplinary perspective. Objective: To analyze the proposed work, which was based on the Problem Based Learning (PBL) methodology, from the construction of standards, through the formalism of Computational Logic, the Visual Turing software to the production of artificial evolutions in the Mirek's Cellebration software, aiming at detailing how a knowledge can be represented. Methodology: Qualitative and descriptive research. Results: Analyzing the process we can say that we first evolved from a given to a simulated knowledge and this represented a knowledge, but it is necessary to go beyond, then seeking other
\end{abstract}


meanings for the representation of a knowledge. We emphasize them from the philosophical, computational and pedagogical point of view reaching the attitude of nonconformity with a single way - deduction - to represent knowledge. Thus, our deviation is through the foundations of transdisciplinarity. Conclusions: Seeking a uniqueness based on transdisciplinary education we conceive that the activity performed in this discipline made it possible to go beyond mathematical formalism and a computer simulation, even emphasizing its great importance, since we allow ourselves to leave a mind conditioned to a creative mind.

Descriptors: Knowledge representation, Rationalism, Interdisciplinarity, Transdisciplinarity.

\title{
CONSTRUCCIÓN DE UNA REPRESENTACIÓN DEL CONOCIMIENTO Y SU ANÁLISIS FILOSÓFICO Y PEDAGÓGICO
}

\begin{abstract}
RESUMEN
Introducción: Este artículo informa sobre la experiencia de realizar un trabajo propuesto por la disciplina de Sistemas de Representación del Conocimiento, uno de los componentes estructurales del Doctorado Multiinstitucional y Multidisciplinario en Difusión del Conocimiento de la Universidad Federal de Bahía, bajo una perspectiva filosófica que reconoce el proceso como racionalista e interdisciplinario y trascendiéndolo a una perspectiva transdisciplinaria. Objetivo: Analizar el trabajo propuesto, que se basó en la metodología de Aprendizaje basado en problemas (PBL), desde la construcción de patrones, pasando por el formalismo de la lógica computacional, el software Visual Turing hasta la producción de evoluciones artificiales en el software Mirek's Cellebration, con el objetivo de detallar cómo se puede representar un conocimiento. Metodología: Investigación cualitativa y descriptiva. Resultados: Analizando el proceso podemos decir que primero evolucionamos de un conocimiento dado a uno simulado y esto representó un conocimiento, pero es necesario ir más allá y luego buscar otros significados para la representación de un conocimiento. Los enfatizamos desde el punto de vista filosófico, computacional y pedagógico, alcanzando la actitud de no conformidad con una única forma, la deducción, para representar el conocimiento. Por lo tanto, nuestra desviación es a través de los fundamentos de la transdisciplinariedad. Conclusiones: Al buscar una singularidad basada en la educación transdisciplinaria, concebimos que la actividad realizada en esta disciplina hizo posible ir más allá del formalismo matemático y una simulación por computadora, incluso enfatizando su gran importancia, ya que nos permitimos dejar una mente condicionada a una mente creativa.
\end{abstract}

Descriptores: Representación del conocimiento, racionalismo, interdisciplinariedad, transdisciplinariedad.

Recebido em: 04.02.2020

Aceito em: 05.02.2021 